\title{
Neurosurgical treatment of chronic pain
}

\author{
FUMIKAZU TAKEDA \\ M.D. \\ Neurosurgery Clinic, Saitama Cancer Center 818 Komuro, Ina, Saitama 362, Japan
}

\section{Introduction}

Neurosurgery is not a first-choice treatment for chronic pain. It is indicated when chronic pain is insufficiently relieved by analgesics, or when medication is effective but causes unacceptable side effects. Neurosurgical procedures may be ablative or augmentative (stimulating). An ablative procedure interrupts pain pathways at one of various levels in the central nervous system (CNS). In contrast, an augmentative procedure is non-destructive and is generally considered to activate the inhibitory system in the CNS, thereby suppressing pain perception.

There is, however, no neurosurgical procedure which affords permanent pain relief. This stems from the fact that pain is not simply the result of stimulation of specific sensory fibres in the peripheral and central nervous systems. As discussed elsewhere, there are two varieties of pain: nociceptive (somatic) and dysaesthetic (deafferentation). Some neurosurgical procedures relieve both nociceptive and dysaesthetic pain, while others relieve only one or other type.

Which procedure should be used in a specific case depends on many variables, including efficacy, indications for use, advantages and disadvantages, limitations and complications. These differ with each procedure. Familiarity with neuroanatomical and neurophysiological concepts of pain mediation and perception, and with a range of techniques, together with the necessary equipment, are all required for the safe and effective use of neurosurgery in the treatment of pain.

It is still sometimes thought that medication is no longer necessary after neurosurgery even if the procedure has resulted in incomplete relief. This misunderstanding must be corrected. The goal of pain treatment is always to provide a pain-free state and, if necessary, it should be achieved through a multi-modality approach.

The following discussion of several neurosurgical procedures is based both on my personal experiences and on data reported in the literature.

\section{Cordotomy}

Cordotomy - section of the spinothalamic tract in the anterolateral quadrant of the spinal cord-used to be carried out through a laminectomy until Mullan et al. $(1963,1965)$ introduced the percutaneous technique. Cordotomy is the treatment of choice to relieve somatic non-dysaesthetic pain of organic origin in C5 dermatome or below. The most common candidates for cordotomy are cancer patients, though cordotomy is also performed for pain of benign origin (Lorenz, 1976). Lipton (1979) states that percutaneous cervical cordotomy (PCC) is not sufficiently used, in spite of its superiority over all other types of pain-relieving procedures. There are two popular varieties of PCC: High $(\mathrm{Cl}-\mathrm{C} 2)$ through a lateral approach and low (C5-C6) through an anterior approach (Lin, Gildenberg and Polakoff, 1966). Both provide excellent pain and thermal anaesthesia in the contralateral half of the body.

The technique has been described in detail by Lipton (1979, 1983). In high PCC, a guide needle is inserted in the lateral cervical region on the contralateral side to the pain. When the needle enters the subarachnoid space, a myelography is performed. It allows the needle to be positioned approximately (Fig. 1). Then an electrode is introduced through the needle, and intraoperative physiological studies are performed: measurement of impedance, electrical stimulation, etc. The latter induces cool or warm tingling in the contralateral half of the body when the electrode is properly placed within the spinothalamic tract. The site of tingling induced by electrical stimulation delineates the area in which pain relief will develop after cordotomy. A radiofrequency coagulation lesion is then produced. A somatotopographic organization for the contralateral half of the body within the lateral spinothalamic tract at $\mathrm{Cl}$ level has been proposed by Tasker (1976a).

The C5-C6 PCC is performed by inserting an electrode from the anterior cervical region through the disc space. Bilateral PCC is carried out on a 


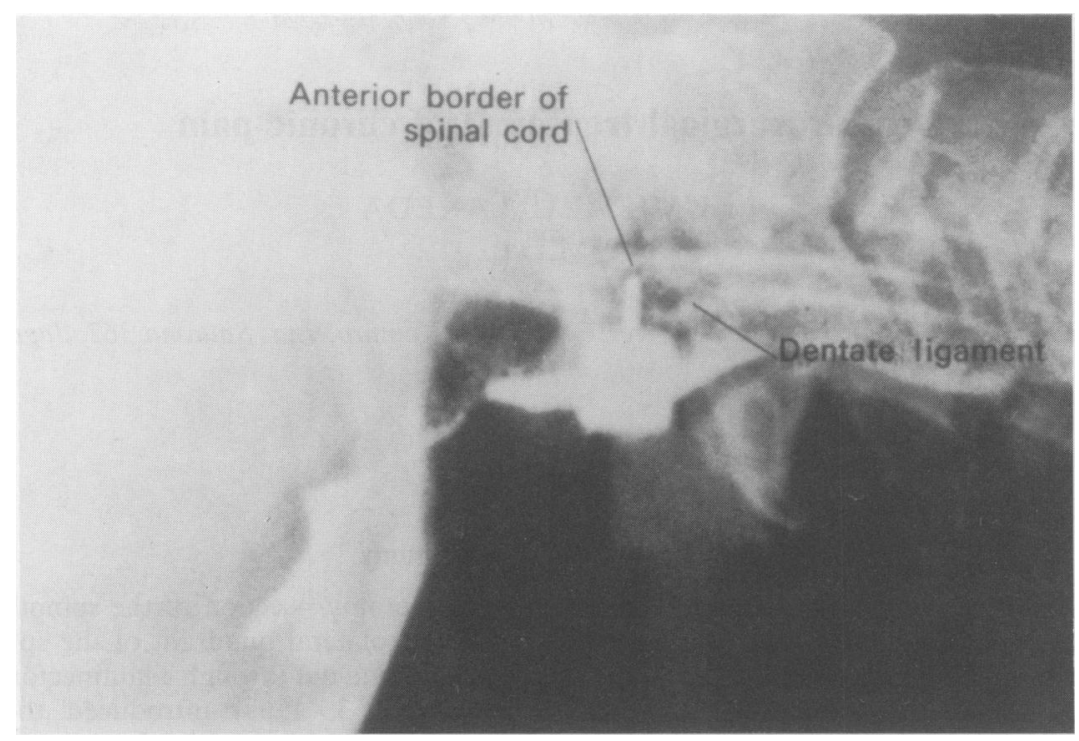

FIG. 1. C1-C2 lateral percutaneous cervical cordotomy. (From Lipton 1979: Relief of Pain in Clinical Practice, Blackwell Scientific Publications, courtesy of the author and publisher).

patient with bilateral pain. Since it is associated with more postoperative hazards than a unilateral cordotomy, Lipton (1979) suggests that high lateral PCC is performed on one side and low anterior PCC on the other side.

Tasker (1976b) reports $96 \%$ incidence of immediate pain relief in 199 consecutive unilateral procedures, and a $66 \%$ incidence of bilateral relief following bilateral procedures. Lipton (1983) performed PCC 809 times on 701 patients and obtained complete pain relief in $86 \%$ of the cases. The effects of a cordotomy tend to wear off within two or three years (Lipton, 1983).

Motor paresis, disturbance of micturition, dysaesthesia, ataxia and Horner's syndrome sometimes occur temporarily after PCC. Respiratory failure, resulting from impairment of automatic respiratory failure during sleep is the most serious potential complication after high PCC, as the reticulospinal tract may be destroyed if the lesion in the spinothalamic tract extends ventrally. Caution should be exercised when a unilateral cordotomy is performed on a patient with contralateral pulmonary dysfunction.

\section{Neurovascular decompression}

The most frequent pathological process in tic douloureux, or classical trigeminal neuralgia, is now considered to be distortion of the trigeminal nerve by cross-compression of blood vessels (Jannetta, 1967, 1977). Neurovascular decompression is done through a small retromastoid craniectomy with supracerebellar exposure using a microsurgical technique. Afte dissection of the blood vessel from the nerve root, spongy pad is placed between the blood vessel afit the nerve. Since Jannetta (1967) popularized this 0 procedure, it has become the most attractive surgical treatment of tic douloureux. Pain can be relieved by this treatment without loss of neural function (Jan- 0 netta, 1977). Preoperative diagnosis is based on $\cong$ clinical assessment as cerebral angiography often $\overrightarrow{\overrightarrow{0}}$ fails to show nerve compression. Intraoperative 3 detection of a tumour compressing the nerve root is not rare. Removal of the tumour results in pain relief.

Jannetta (1977) reports excellent results following surgery in 200 patients with tic douloureux. In the 3 . first 100 patients, he found compression-distortion of $\frac{0}{3}$ the root entry zone of the trigeminal nerve by normal $\stackrel{3}{\circ}$ blood vessels in 88 cases, by tumours in four cases, by arteriovenous malformations in two cases and by multiple sclerosis plaque in six cases. Recurrent pain 음 is documented in nine cases out of 200 . This usually results from slippage of the pad or missing a second vascular loop. Both situations can be corrected by $N$ further surgery. Trigeminal rhizotomy is indicated for multiple sclerosis plaque.

Postoperative complications, e.g., meningitis, cerebellar infarction and haematoma, and hearing loss 0 occur less often with greater surgical experience.o Glossopharyngeal neuralgia can also be relieved by neurovascular decompression (Laha and Jannetta, $\stackrel{\oplus}{\stackrel{\oplus}{?}}$ 1977). 


\section{Cranial nerve rhizotomy}

\section{Trigeminal rhizotomy}

As stated by Tew and Keller (1977), ophthalmological complications and a significant mortality rate following retrogasserian trigeminal rhizotomy using a direct intracranial approach have encouraged the development of alternative procedures such as percutaneous injection (Harris, 1940) and coagulation (Kirschner, 1932). Sweet and Wepsic (1974) revised the percutaneous radiofrequency coagulation technique, preserving touch sensation in the zone rendered analgesic. Percutaneous radiofrequency rhizotomy of the trigeminal nerve is indicated, at present, for the alleviation of tic douloureux, mainly in elderly patients, because it can be carried out under local anaesthesia. It is also performed in the treatment of some other types of chronic facial pain e.g., cancer pain, but it often fails to be effective against postherpetic neuralgia and atypical facial pain.

Through fluoroscopic control, the foramen ovale is punctured percutaneously from the cheek, using three landmarks (Fig. 2). A brief contracture of the masseter muscle and a wince indicate that the needle or electrode has entered the foramen ovale (Fig. 3). The position of the electrode is adjusted further according to the patient's response to electrical stimulation elicited through the electrode. Electric stimulation produces paroxysmal bouts of pain in the domain of each ipsilateral sensory rootlet. When the electrode is placed in contact with the motor root, stimulation produces masseter contraction. Postoperative motor dysfunction is thus eliminated. After the correct position of the electrode is finally determined, the sensory root is destroyed with a radiofrequency current.

Sweet and Wepsic (1974) obtained relief of trigeminal neuralgia in $91 \%$ out of 217 patients, with a recurrence rate of $22 \%$ in 125 patients over the next 2.5-6 years. Based on results from 400 patients, Tew, van Loveren and Keller (1982) report that 61\% obtained excellent relief and $13 \%$ good relief, while $5 \%$ have undesirable side effects, such as troublesome dysaesthesia in the face, and $1 \%$ have no relief. Pain recurred in $20 \%$ of the patients during a follow-up period which averaged 6 years.

The most serious complication is production of an anaesthetic cornea, which sometimes results in corneal scarring. Dysaesthesia in the analgesic region, masseter weakness and extraocular cranial nerve palsies are also reported (Tew et al., 1982).

\section{Glossopharyngeal rhizotomy}

This nerve can be approached at the posterior foramen lacerum through percutaneous puncture under physiological control. Radiofrequency coagulation with a very selective morbidity (sensory deficit in the ninth nerve) is achieved. Broggi and Siegfried (1979) report long-lasting relief in two cases with cancer pain.

\section{Combined multiple rhizotomies (CMR)}

CMR of the fifth and ninth cranial nerves and, if necessary, of the upper cervical ones, have also been proposed (Pagni, 1979b).

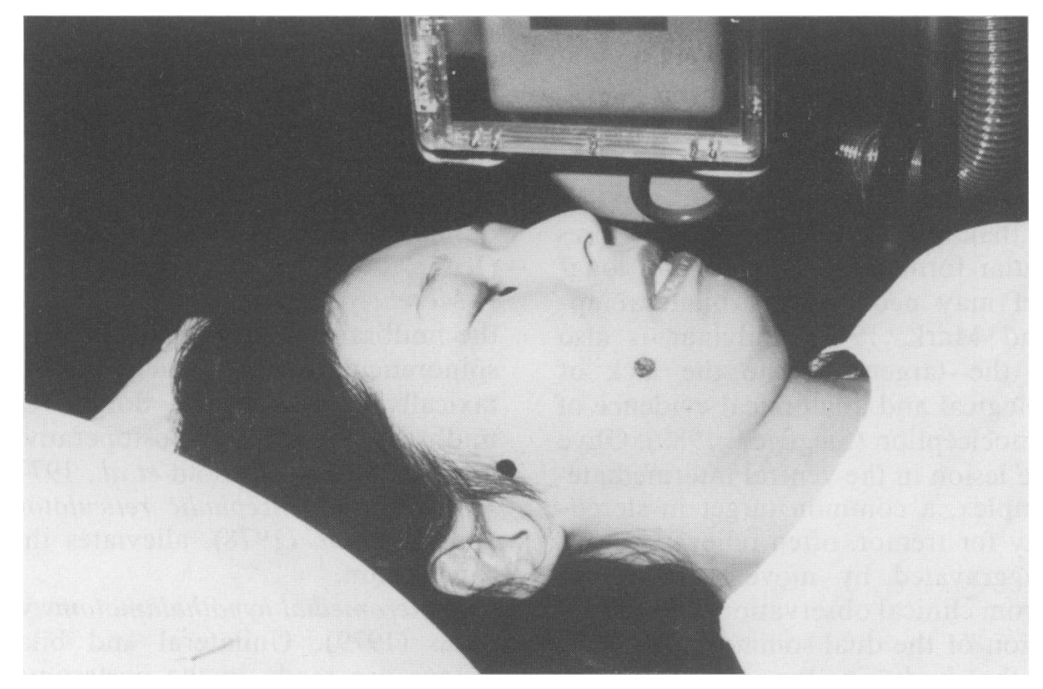

FIG. 2. Three landmarks in percutaneous trigeminal rhizotomy: a point $3 \mathrm{~cm}$ anterior from the external auditory meatus, a point beneath the medial aspect of the pupil and a point $2.5 \mathrm{~cm}$ lateral to the oral commissure. The first two points indicate the site of the foramen ovale and the third is the point at which the needle penetrates the skin (Tew and Keller, 1977). 


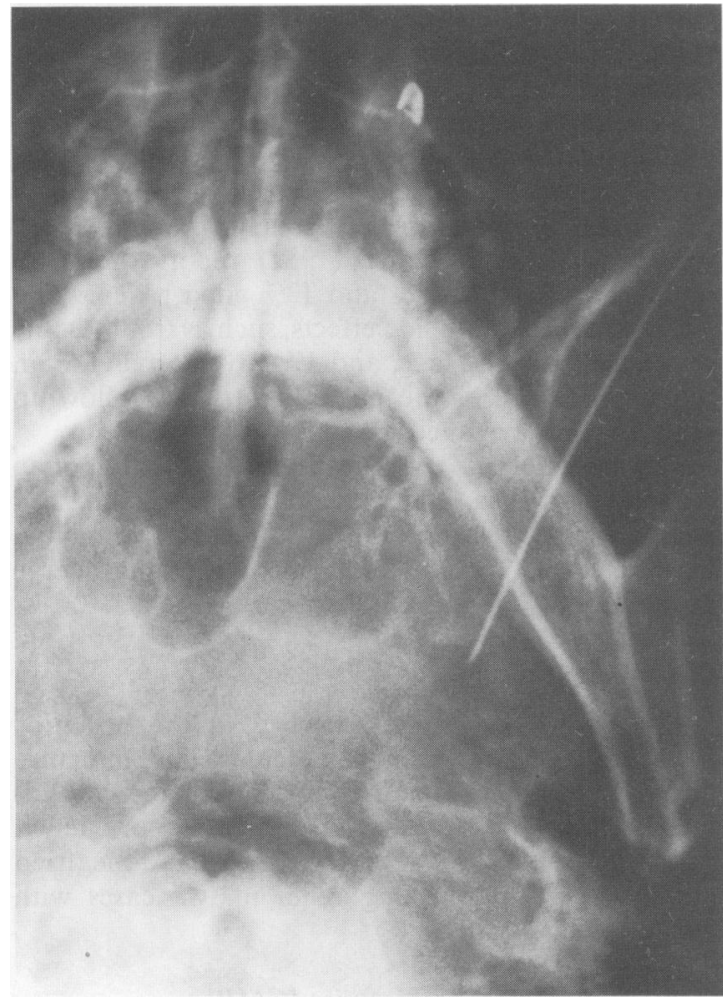

FIG. 3. Roentgenogram in axial view, showing a needle approaching the foramen ovale.

\section{Thalamotomy}

Although it has been disputed, it is now generally agreed that the centre-median, parafascicular, and intralaminar complexes are the best target nuclei. Their destruction results in pain relief without sensory loss and risk of central pain (Mark, Ervin and Hackett, 1960; Mark, Ervin and Yakovlev, 1963). Since the medial thalamic nuclei receive pain fibres through the reticular formation, effective and longlasting pain relief may necessitate a bilateral approach (Roth and Mark, 1973). Pulvinar is also included among the targets despite the lack of significant physiological and anatomical evidence of its role in central nociception (Siegfried, 1980). Ohye (1983) finds that a lesion in the ventral intermediatecentre lateral complex, a common target in stereotaxic thalamotomy for tremor, often relieves central pain which is aggravated by movement. Tasker (1976b) reports, from clinical observation, a diagrammatic representation of the dual somatotopographic organization of the body in the somatosensory thalamus, i.e. in the posterior portion of the ventrobasal complex and posteriorly adjacent nuclei. The advantages of thalamotomy are that the procedure carries minimal mortality and morbidity, and it controls pain over the entire opposite side of the bodya (Richardson, 1979), though pain often recurs severafmonths later.

Thalamotomy is carried out through a stereotaxic surgical procedure under local anaesthesia (Figs. $\frac{1}{5}$ and 5). Access to target nuclei is carried out preciselye with the aid of both topographical measurement and physiological studies such as thalamic stimulation, and the recording of spontaneous electrical activityes and evoked potentials in response to periphera 5 natural stimuli. A radiofrequency current is appliedto produce a lesion of an appropriate size.

Postoperative complications include temporarys drowsiness, motor weakness, hallucinations and? other neurological problems. These can be mini $=$ mized by conscientious intraoperative physiologica! studies.

\section{Other ablative procedures}

Commissural myelotomy consists of section of the pain fibres at the midline of the spinal cord where they cross to ascend in the contralateral anterioro quadrant: a matter of historical interest rather than of practical value (Pagni, 1979a).

Medullary tractotomy is spinothalamic tractotom $y_{-}$ at medullary level to relieve pain in the upper lifor (Birkenfeld and Fisher, 1963; Pagni, 1979a).

Medullary trigeminal tractotomy, proposed Sjöqvist (1938), has been refined with intraoperativeo physiological studies, radiofrequency coagulations and microsurgical technique (Bricolo, 1979). The operation is done through suboccipital craniectomy and high cervical laminectomy. A radiofrequency current is used to produce one or more lesions in the्ड descending trigeminal tract. These lesions relieve 3 pain in the face and head with preservation of touch sensation and corneal reflex (Bricolo, 1979).

Selective glossopharyngeal tractotomy in the me음 dulla oblongata relieves glossopharyngeal neuralgiq (Kunc, 1965).

Mesencephalotomy attacks the pain pathways in the midbrain by interrupting the spinothalamic and spinoreticulothalamic tracts. An electrode is stereotaxically placed in the dorsal tegmentum of the midbrain. The rate of postoperative complication is relatively high (Nashold et al., 1977).

Rostral mesencephalic reticulotomy, proposed by Amano et al. (1978), alleviates thalamic pain and cancer pain.

Posteromedial hypothalamotomy was carried out bxw Sano (1979). Unilateral and bilateral stereotaxie lesions are made in the posteromedial (ergotropicos hypothalamus which is the continuation of theD periaqueductal gray. This procedure was more effec? tive in the treatment of intractable cancer pain than 


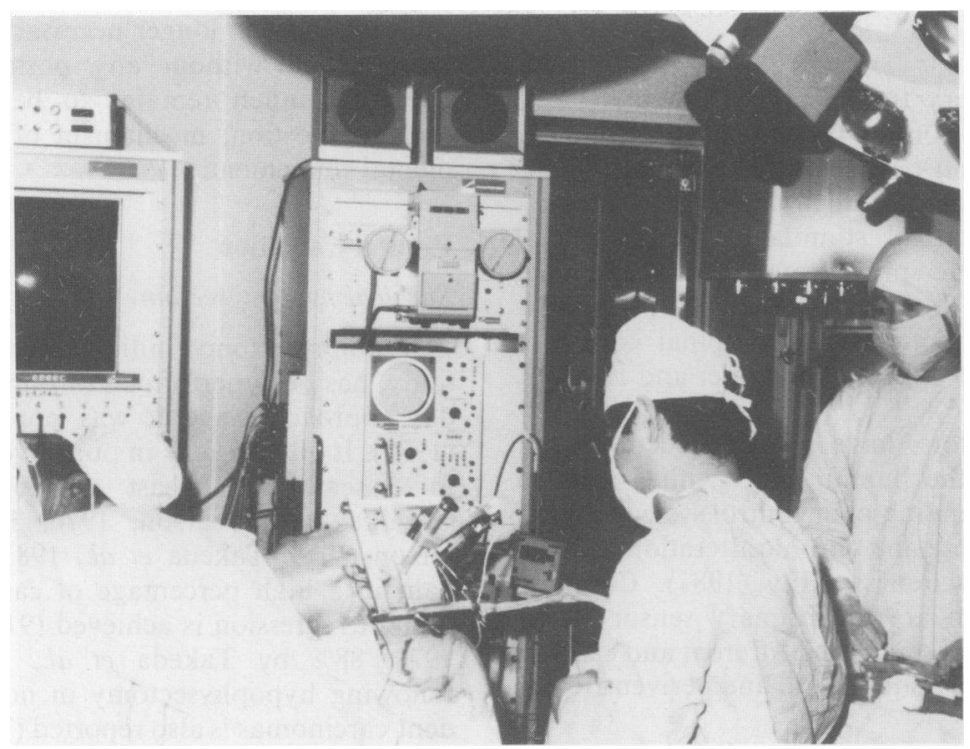

pain related to other causes. This procedure was done initially in psychologically aggressive patients (Sano et al. 1970).
Ventral cingulumotomy is a procedure to relieve pain suffering: a multifaceted reaction to chronic pain (Foltz and White, 1962). 


\section{Deep brain stimulation}

This contemporary therapeutic advance is based partly on the gate control theory of pain (Melzack and Wall, 1965) and partly on the discovery of the descending pain control system mediated by endogenous opioids. Electrical stimulation of peripheral nerves may close the spinal 'gate', thereby reducing spontaneous pain (Wall and Sweet, 1967). Stimulation of the dorsal column in the spinal cord also produces pain relief (Shealy, Mortimer and Hagfors, 1970; Nashold, 1976).

Many investigators have placed electrodes in several targets in the human CNS with a view to activating the descending pain control system, and so to produce both acute and chronic alterations of pain perception and awareness (Ray, 1981). Common targets in the brain are the primary sensory relay nuclei of the thalamus and their afferent and efferent pathways and the periaqueductal and periventricular gray substance.

An electrode is stereotaxically placed in one of these targets. The patient's response to stimulation is essential to determine the final position of the electrode. Temporary stimulation may make the pain disappear for a varying length of time, though in some patients it may only reduce the pain or even increase it. After the effectiveness of stimulation is confirmed, the electrode is connected to a subcutaneous radio-receiver, activated transcutaneously by an external radiotransmitter. Patients control the transmitter to produce appropriate electrical stimuli to suppress the pain as necessary.

In Ray's report (1981), some 850 cases are documented, all treated by outstanding experts. There is considerable variation in the clinicians' personal experience of pain cases, targets used and results. Suppression of both somatic and dysaesthetic pain ranged from $50 \%$ to $75 \%$. Gybels (1983) reports the results of a survey by the European Cooperative Study Group. Stimulation in the thalamic relay nuclei (VPL-VPM) and their afferent and efferent pathways resulted in successful suppression of dysaesthetic (deafferentation) pain in 106 patients out of 182 , while it failed to relieve neurogenic and cancer pain. Stimulation in periaqueductal nuclei and periventricular gray substances resulted in the successful relief of dysaesthetic pain in 19 patients out of 76, neurogenic pain in 24 patients out of 31 , and cancer pain in 17 patients out of 36 . There is no obvious explanation of why stimulation successfully suppresses pain in some patients and fails to do so in others with very similar syndromes (Adams, 1976).

Electrical stimulation of the CNS is a promising procedure in relieving chronic pain because, theoretically, it is a non-destructive approach and, when stimulation is no longer necessary, the electrode can be removed without any postoperative sequelae However, much remains to be determined about patient selection, mechanism of action and instru $\overline{\bar{\sigma}}$ mental refinement.

\section{Pituitary ablation}

\section{Surgical hypophysectomy}

Hypophysectomy, initially carried out via a craniotomy, has been performed through the transsphenoi? dal approach since it was popularized by Hardy (1971). It often results in objective tumour regressiow in disseminated breast and prostate carcinomag (Brodkey and Pearson, 1976; Tindall, Payne and Nixon, 1979; Takeda et al., 1983a). It also relieves pain in a high percentage of cases, whether or nof tumour regression is achieved $(91 \%$ by Tindall $e$ et al. 1979; 88\% by Takeda et al., 1983a). Pain reliefo following hypophysectomy in non-hormone depener dent carcinomas is also reported (Tindall et al., 1977)? Hypophysectomy is not effective against non-cancer pain. Surgical hypophysectomy is a major surgica! intervention and is not indicated in high-risk patients (Table 1). Corticosteroid replacement therapy is necessary postoperatively. Diabetes insipidus is seen in the majority of cases.

\section{Pituitary neuroadenolysis}

Moricca (1974) injected ethanol into the sella turcica to relieve cancer pain. This technique is called neuroadenolysis. Under neuroleptoanalgesia a needle is inserted into the sella turcica through op nostril (Fig. 6). Pure ethanol, usually about $2 \mathrm{ml}$, is instilled into the sella turcica very slowly. Theo advantages of neuroadenolysis are its simplicity repeatability if pain recurs, acceptance even by terminally ill patients, minimal post-treatment dis comfort and short hospital stay (Table 1).

Pain relief is frequently obtained immediately after ethanol instillation, and lasts for weeks, months of sometimes over a year. Moricca (1974) reports that he achieved pain relief in almost all of the patients은 However, Lipton et al. (1978) state that one-third of the patients obtains complete pain relief and the second one-third has partial relief, while the remain ing one-third is unaffected. Takeda et al. $(1983 \mathrm{a})$ performed neuroadenolysis 136 times on 102 patients and obtained satisfactory relief of pain in $80 \%$ of the cases: $95 \%$ in $\mathbf{4 3}$ hormone-dependent carcinomas, and 69\% in 59 non-hormone-dependent carci $\omega$ nomas.

Visual field defects are seen in a few patients whefe instilled ethanol damages the optic chiasm. Unilateral ophthalmoplegia is also temporarily but infrequently observed. The author and colleagues have 
TABLE 1. Comparing neuroadenolysis with surgical hypophysectomy

\begin{tabular}{|c|c|c|}
\hline & Neuroadenolysis & $\begin{array}{l}\text { Surgical } \\
\text { hypophysectomy }\end{array}$ \\
\hline Technique & Simple & Major and traumatic \\
\hline Time for performance & Short & Time-consuming \\
\hline Suitability in high-risk patients & Suitable & Limited \\
\hline Repeatability in pain recurrence & Possible & Impossible \\
\hline Postoperative discomfort & Minimal & Considerable \\
\hline Acceptance by terminal patients & Excellent & Poor \\
\hline Pituitary dysfunction following & Slight to & \\
\hline procedure & marked & Always marked \\
\hline Hospital stay & Short & Not short \\
\hline \multicolumn{3}{|l|}{ Percentage pain relief: } \\
\hline hormone-dependent tumours & $95 \% *$ & $88 \% *, 91 \% \dagger$ \\
\hline non-hormone-dependent tumours & $69 \% *$ & $67 \% \neq$ \\
\hline \multicolumn{3}{|l|}{ Objective tumour regression rate } \\
\hline in hormone-dependent tumours & $6.9 \% *$ & $39 \% * 36 \% \dagger$ \\
\hline
\end{tabular}

*Takeda et al., 1983a: †Tindall et al., 1979; ¥Tindall et al., 1977.

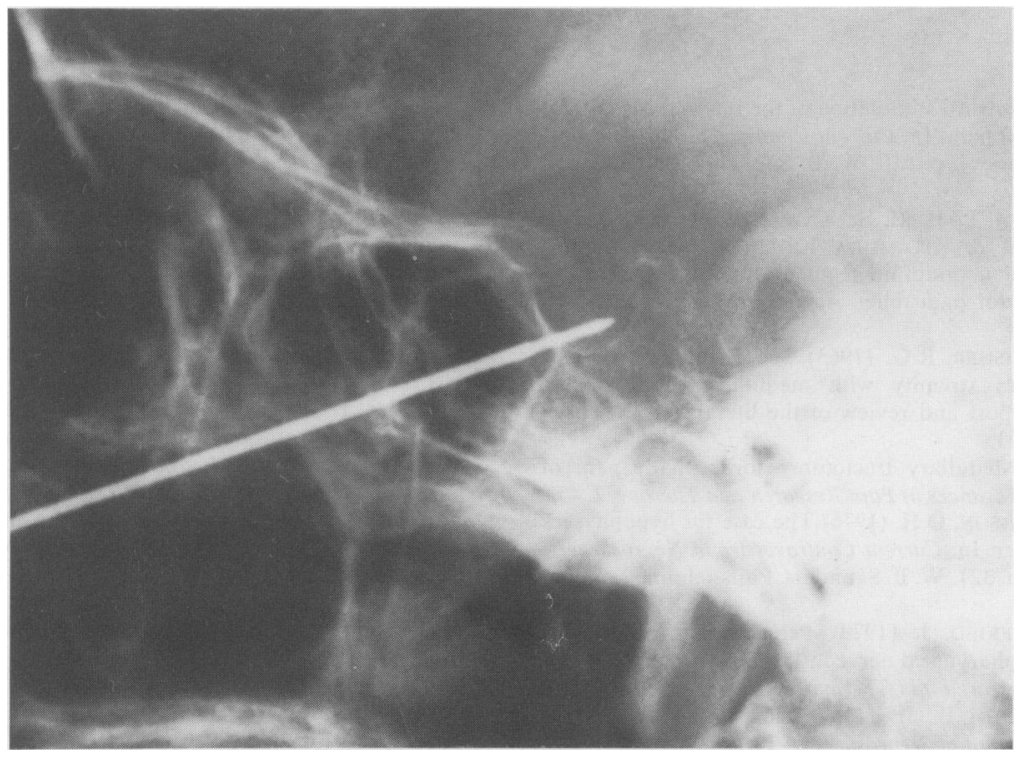

FIG. 6. Pituitary neuroadenolysis. A needle is placed in the sella turcica.

recently utilized instillation of aqueous phenolmetrizamide solution instead of ethanol to preclude ophthalmological complications. This solution acts as effectively as ethanol does, and is visible on a TVmonitor. The surgeons can stop injecting the solution if they observe its unwanted spread to the suprasellar cistern.

Some clues in elucidating the mechanism by which neuroadenolysis relieves cancer pain were recently reported (Takeda et al. 1983b, c). There are evidences that the alcohol instilled into the sella turcica acts as a destructive as well as a stimulative agent on the hypothalamopituitary axis (Lipton et al.,
1978; Lipton, 1979; Takeda et al. 1983b, c). When investigating hypothalamo-pituitary interactions, continuous elevation of adrenocorticotrophin, thyrotrophin-releasing hormone, arginine-vasopressin and beta-lipotropin is observed in the cerebrospinal fluid after neuroadenolysis. There is no significant increase of endorphins in the cerebrospinal fluid. Pain threshold determination indicates increased Cfibre threshold following neuroadenolysis. Observation indicates that the increase of peptides in the cerebrospinal fluid, which are mainly synthesized in the hypothalamopituitary axis, would exert a suppressive effect on the mediation and perception of 
cancer pain through C-fibres and the CNS (Takeda et al. 1983b).

\section{Other procedures of pituitary ablation}

Isotope implantation into the pituitary gland (Johnson, West and Rutledge, 1958), radiofrequency thermal hypophysectomy (Zervas and Gordy, 1969) and cryohypophysectomy (Gye et al., 1979) also alleviate pain in hormone-dependent carcinomas.

\section{Acknowledgment}

The author expresses his sincere appreciation to Professor Chihiro Ohye, Department of Neurosurgery, Gunma University School of Medicine, Japan, for his valuable suggestions, Dr Sampson Lipton, Medical Director, Pain Foundation, Walton Hospital, Liverpool, for his permission to use figure in this paper, and $\mathrm{Mr}$ Kenneth Anderson, Lecturer, Aoyama Gakuin University, Tokyo, for his assistance in preparation of the manuscript.

\section{References}

ADAMS, J.E. (1976) Electrical stimulation of the internal capsule for the control of central pain. In: Current Controversies in Neurosurgery. (Ed. T. P. Morley), p. 510. W. B. Saunders, Philadelphia, London, Toronto.

amano, K., Tanikawa, T., Iseki, H., Kawabatake, H., Notani, M., Kawamura, H. \& Kitamura, K. (1978) Single neuron analysis of the human midbrain tegmentum. Rostral mesencephalic reticulotomy for pain relief. Applied Neurophysiology, 41, 66.

BIRKENFELD, R. \& FiSHER, R.G. (1963) Successful treatment of causalgia of upper extremity with medullary spinothalamic tractotomy. Case report and review of the literature. Journal of Neurosurgery, 20, 303.

BRICOLO, A. (1979) Medullary tractotomy for cephalic pain of malignant disease. Advances in Pain Research and Therapy, 2, 453.

BrodkeY, J.S. \& PEARSON, O.H. (1976) The case for hypophysectomy in breast cancer. In: Current Controversies in Neurosurgery. (Ed. T. P. Morley), p. 321. W. B. Saunders, Philadelphia, London, Toronto.

Broggi, G. \& Siegfried, J. (1979) Percutaneous differential rhizotomy of glossopharyngeal nerve in facial pain due to cancer. Advances in Pain Research and Therapy, 2, 469.

FolTZ, E.L. \& White, L.E., Jr. (1962) Pain 'relief' by frontal cingulumotomy. Journal of Neurosurgery, 19, 89.

GYBELS, J. (1983) Analgesic brain stimulation in chronic pain in man and rat. In: Current Topics in Pain Research and Therapy. (Eds. Yokota, T. and Dubner, R.), p. 137. Excerpta Medica, Amsterdam, Oxford, Princeton.

Gye, R.S., Stanwarth, P.A., Stewart, J.A. \& Adams, C.B.T. (1979) Cryohypophysectomy for bone pain of metastatic breast cancer. Pain, 6, 201.

HARDY, J. (1971) Transsphenoidal hypophysectomy. Journal of Neurosurgery, 34, 582.

HARRIS, W. (1940) An analysis of 1,433 cases of paroxysmal trigeminal neuralgia (trigeminal-tic) and the end-results of gasserian alcohol injection. Brain, 63, 209.

JANNETTA, P.J. (1967) Arterial compression of the trigeminal nerve at the pons in patients with trigeminal neuralgia. Journal of Neurosurgery, 26, 159.

JANNETTA, P.J. (1977) Treatment of trigeminal neuralgia by suboccipital and transtentorial cranial operations. Clinical Neurosurgery, 24, 583.

JohNSON, P.C., WEST, K.M. \& RUTLEDGE, B.J. (1958) Destruction of the hypophysis with radioactive colloidal chromic phosphate in cancer of the prostate. Journal of Neurosurgery, 15, 519.
KIRSCHNER, M. (1932) Zur Elektrokoagulation des Ganglion Gasseri. Zentralblatt für Chirurgie, 47, 2841.

Kunc, Z. (1965) Treatment of essential neuralgia of the 9th nerve by. selective tractotomy. Journal of Neurosurgery, 23, 494.

LAHA, R.K. \& JANNETTA, P.J. (1977) Glossopharyngeal neuralgia. Journal of Neurosurgery, 47, 316.

Lin, P.M., GildenberG, P.L. \& PolakofF, P.P. (1966) An anterior approach to percutaneous lower cervical cordotomy. Journal of Neurosurgery, 25, 553.

LIPTON, S. (1979) Relief of Pain in Clinical Practice. Blackwell $\overparen{\Phi}$ Scientific Publications, Oxford.

LIPTON, S. (1983) Percutaneous cervical cordotomy. In: Current Topics in Pain Research and Therapy. (Eds. T. Yokota and R. $\overrightarrow{-}$ Dubner), p. 285. Excerpta Medica, Amsterdam, Oxford, Prince-.? ton.

Lipton, S., Miles, J., Williams, N. \& Bark-Jones, N. (1978) $\vec{\omega}$ Pituitary injection of alcohol for widespread cancer pain. Pain, 5 73.

LORENZ, R. (1976) Methods of percutaneous spino-thalamic 3 tract section. Advances and Technical Standards in Neurosurgery, $\dot{\sigma}$ 3, 123.

MARK, V.H., ERVIN, F.R. \& HACKETT, T.P. (1960) Clinical aspects of stereotactic thalamotomy in the human. Part I. The treatment $\vec{O}$ of chronic severe pain. Archives of Neurology, 3, 351 .

MARK, V.H., ERVIN, F.R. \& YAKOVLEV, P.I. (1963) Stereotactic of thalamotomy III. The verification of anatomical lesion sites in the human thalamus. Archives of Neurology, 8, 528.

MELZACK, R. \& WALL, P.D. (1965) Pain mechanisms: A new theory. Science, 150, 971.

MORICCA, G. (1974) Neuroadenolysis for the antalgic treatment of advanced cancer patients. In: Recent Advances on Pain. (Eds. J. J. Bonica, P. Procacci and C. A. Pagni), p. 313. C. C. Thomas, Springfield.

Mullan, S., Harper, P.V., Hekmatpanah, J., Torres, H. \& DUBBIN, G. (1963) Percutaneous interruption of spinal-pain trats by means of a strontium 90 needle. Journal of Neurosurgery, $20,+$ 931.

Mullan, S., Hekmatpanah, J., Dubben, G. \& Beckman, F. (1965) Percutaneous, intramedullary cordotomy utilizing unipolar anodal electrolytic lesion. Journal of Neurosurgery, 22, 548.

NASHOLD, B.S., Jr. (1976) Electrical stimulation of the skin, peripheral nerves, or dorsal column for pain relief. In: Currento Controversies in Neurosurgery. (Ed. T. P. Morley), p. 502. W. B. Saunders, Philadelphia, London, Toronto.

NASHOLD, B.S., Jr., SLAUGhTER, D.G., WILSON, W.P. \& ZoRUB, D. Ō (1977) Stereotatic mesencephalotomy. Progress in Neurological Surgery, 8, 35.

OHYE, CH. (1983) Stereotaxic thalamotomy for treatment of tha-C lamic pain. Presented at the 5th Japan Chapter of International Association for the Study of Pain. Tokyo.

PAGNI, C.A. (1979a) General comments on ablative neurosurgical procedures. Advances in Pain Research and Therapy, 2, 405.

PAGNI, C.A. (1979b) Cancer pain in the head and neck: Role of? neurosurgery. Advances in Pain Research and Therapy, 2, 543.

RAY, C.D. (1981) Electrical and chemical stimulation of the CNS by direct means for pain control: Present and future. Clinical Neurosurgery, $28,564$.

RICHARDSON, D.E. (1979) Role of neurosurgery in pain involving the chest and brachial plexus. Advances in Pain Research ando Therapy, 2, 577.

ROTH, D.A. \& MARK, V.H. (1973) Thalamotomy for relief of pain. N In: Neurological Surgery. (Ed. J. R. Youmans), p. 1783. W. B.Saunders, Philadelphia, London, Toronto.

SANO, K. (1979) Stereotaxic thalamotomy and posteromedial hypo-N thalamotomy for the relief of intractable pain. Advances in Pain $\omega$ Research and Therapy, 2, 475.

Sano, K., Mayanagi, Y., Sekino, H., Ogashiwa, M. \& Ishijima,e B. (1970) Results of stimulation and destruction of the posterior hypothalamus in man. Journal of Neurosurgery, 33, 689.

SHEALY, C.N., MORTIMER, J.T. \& HAGFORS, N.R. (1970) Dorsal column electroanalgesia. Journal of Neurosurgery, 32, 560. 
SIEGFrIED, J. (1980) Neurosurgery. In: The Continuing Care of Terminal Cancer Patients. (Eds. R. G. Twycross and V. Ventafridda), p. 147. Pergamon Press, Oxford.

SJÖQVIST, O. (1938) Studies on pain conduction in the trigeminal nerve. A contribution to surgical treatment of facial pain. Acta Psychiatrica et Neurologica, Suppl. 17.

SWEET, W.H. \& WEPSIC, J.G. (1974) Controlled thermocoagulation of trigeminal ganglion and rootlets for differential destruction of pain fibers. Part I: Trigeminal neuralgia. Journal of Neurosurgery, 40, 143.

Takeda, F., Fuji, T., Uki, J., Fuse, Y., Tozawa, R., Kitani, Y. \& FUJITA, T. (1983a) Cancer pain relief and tumor regression by means of pituitary neuroadenolysis and surgical hypophysectomy. Neurologia Medico-Chirurgica, 23, 41.

Takeda, F., FujII, T., Uki, J., Tozawa, R., Fuse, Y., Kitani, Y. \& FuJITA, T. (1983b) Alterations of hypothalamopituitary interaction and pain threshold following pituitary neuroadenolysis. A clinical investigation of the mechanism of cancer pain relief. Neurologia Medico-Chirurgica, 23, 551.

TAKeda, F., UKI, J., FuJII, T., Kitani, Y. \& Fujita, T. (1983c) Pituitary neuroadnolysis to relieve cancer pain: Observation of spread of ethanol instilled into the sella turcica and subsequent changes of the hypothalamopituitary axis at autopsy. Neurologia Medico-Chirurgica, 23, 50.

TASKER, R.R. (1976a) Somatotopographic representation in the human thalamus, midbrain, and spinal cord. The anatomical basis for the surgical relief of pain. In: Current Controversies in Neurosurgery. (Ed. T. P. Morley), p. 485. W. B. Saunders, Philadelphia, London, Toronto.

TASKER, R.R. (1976b) Merits of percutaneous cervical cordotomy over the open operation. ibid, p. 496.

TEW, J.M.. Jr. \& KELLER, J.T. (1977) The treatment of trigeminal neuralgia by percutaneous radiofrequency technique. Clinical Neurosurgery, 24, 557.

TEW, J. M., Jr., VAN LOVEREN, H. \& KelleR, J.T. (1982) Trigeminal neuralgia. Neurosurgeons (Proceedings of the 2 nd annual meeting of the Japanese Congress of Neurological Surgeons), 2, 251.

Tindall, G.T., NiXon, D.W., Christy, J.H. \& NeILl, J.D. (1977) Pain relief in metastatic cancer other than breast and prostate gland following transsphenoidal hypophysectomy. A preliminary report. Journal of Neurosurgery, 47, 659.

Tindall, G.T., PAYNe, N.S. \& Nixon, D.W. (1979): Transsphenoidal hypophysectomy for disseminated carcinoma of the prostate gland. Results in 58 patients. Journal of Neurosurgery, 50, 275.

WALL, P.D. \& SWEET, W.H. (1967) Temporary abolition of pain in man. Science, 155, 108.

ZERVAS, N.T. \& GORDY, P.D. (1969): Radiofrequency thermal hypophysectomy. Technical note. Journal of Neurosurgery, 30, 511. 